\title{
The anterior segment of the eye in diabetes
}

This article was published in the following Dove Press journal:

Clinical Ophthalmology

3 May 2012

Number of times this article has been viewed

\section{CO Adeoti' \\ MA Isawumi' \\ AO Ashaye ${ }^{2}$ \\ BV Olomola'}

'Ladoke Akintola University of Technology Teaching Hospital, Osogbo, Nigeria; ${ }^{2}$ Ophthalmology Department, University College Hospital, Ibadan, Nigeria
Correspondence: CO Adeoti Department of Ophthalmology, College of Health Sciences, PO Box 979, Osogbo,

Osun State, Nigeria

Tel +2348033742827

Email caroladeoti200I@yahoo.co.uk
Purpose: A prospective study to examine the anterior segment of the eye in patients with diabetes mellitus.

Materials and methods: The anterior segments of the eyes of 181 patients with diabetes mellitus were examined. The commonest finding in the lids was warts, followed by poliosis and chalazia, and, in the conjunctiva, tortuous conjunctival vessels inferiorly (36.50\%), pterygium (14.92\%), and pingueculum (14.37\%). Corneal sensitivity was reduced in 25 (13.80\%) patients. Iris atrophy was the commonest finding in the iris. Dilatation of the pupil was delayed in $34(18.79 \%)$ patients. Cataract was found in $119(65.75 \%)$ patients. Forty-one (22.65\%) patients had intraocular pressure greater than $21 \mathrm{mmHg}$. Seven (3.87\%) patients, four (2.21\%) patients, and one $(0.55 \%)$ patient had seventh, third, and fourth palsy, respectively. No patient had sixth nerve palsy.

Conclusion: Primary care physicians and other allied health care professionals who are first in contact with patients are enjoined to familiarize themselves with the anterior segment features of diabetes mellitus and take necessary action when they are detected.

Keywords: diabetes mellitus, eye, anterior segment

\section{Introduction}

Diabetes mellitus, characterized by sustained hyperglycemia secondary to lack of or diminished efficacy of endogenous insulin, causes significant morbidity and mortality in multiple systems of the body. It is no longer a disease of the affluent or industrialized nations. ${ }^{1}$ It has the highest prevalence among the populations of developing countries and in migrant and minority communities in industrialized countries. ${ }^{1}$ In the UK, $1 \%-2 \%$ of the population is affected, and in Nigeria it is estimated that about two million people have diabetes, though only approximately half of them are aware of it. ${ }^{1}$

Diabetic eye disease is becoming an increasing problem in developing countries, due to longer life expectancy and a higher incidence of diabetes. ${ }^{1}$

In a study in Southern India, an average of 45 patients per month presented with advanced diabetic retinopathy. ${ }^{2}$ Only a few of these patients were referred for examination, suggesting that there is a need to improve awareness amongst the community and health care professionals. ${ }^{2}$

In the eye, manifestations are found in almost every part - orbit and lids and the anterior and posterior segments. Most previous authors have concentrated on diabetic retinopathy, ${ }^{3,4}$ but this disease can affect virtually every part of the eye and sometimes can significantly affect vision. Primary eye care workers and other professionals can 
easily examine the anterior segment of the eye for features of diabetes mellitus if trained to do so.

Orbital and lid features include boils, chalazia, xanthelasma, cranial nerve palsies (seventh, sixth, third, and fourth), and cellulitis. Conjunctival features include tortuous and dilated vessels, which are commonly found in the inferior bulbar region, pingueculae, and pterygia. Tortuosity and dilatation of veins are part of the microvascular abnormalities found in diabetes. ${ }^{5}$

Corneal abnormalities such as superficial punctate keratitis, recurrent corneal erosion, persistent epithelial defects, and damage to the corneal endothelium are also commonly found in patients with diabetes mellitus. ${ }^{6}$ Some studies have shown increased corneal thickness in diabetic patients ${ }^{7-9}$ and persistent corneal edema after cataract extraction and vitrectomy, not attributable to epithelial defects, suggesting abnormal function of the corneal endothelium. ${ }^{10,11}$ Diabetic patients have also been found to have reduced corneal sensitivity as part of generalized sensory neuropathy. ${ }^{12}$ In spite of the unspecific character of the damage and the subjectivity of the measurement, corneal sensitivity is an interesting parameter to take into consideration among diabetic patients. ${ }^{13}$

Diabetes also influences lens transparency and pharmacological pupil dilatation. Cataract occurring in diabetic patients can be due to the diabetes itself or to accelerated senile cataract, in which case the cataract occurs earlier than normal. As with retinopathy, the duration and control of the diabetes are important factors in cataract development and management. ${ }^{14}$ In one study, 987 patients $(53 \%)$ had cataracts in one or both eyes. ${ }^{2}$

Changes in the refractive state of the eye may indicate the onset of diabetes. ${ }^{14}$ These may be myopia or hypermetropia. Myopia may be due to an increase in the thickness and curvature of the crystalline lens. ${ }^{14}$

Cranial nerve palsies are common in diabetes mellitus, with the facial nerve (seventh) being the most commonly affected, followed by the abducens, oculomotor, and trochlear. ${ }^{15}$

The association between diabetes mellitus and glaucoma in the literature is equivocal. Some researchers have not found an association, ${ }^{16}$ whereas others in Australia found the prevalence of open-angle glaucoma to be greater in people with diabetes than in the normal population. ${ }^{17}$ Sharma ${ }^{2}$ found glaucoma in 106 patients (6\%).

Iris atrophy, ectropion uvea, and rubeosis iridis are also seen in diabetic patients.

The aim of this study is to investigate the anterior segment findings in patients with diabetes mellitus in this environment. There has been no such study in the southwestern part of Nigeria.

\section{Materials and methods}

After obtaining informed consent, 181 consecutive patients with the diagnosis of diabetic mellitus were included in the study. The diagnosis was based on classical symptoms of weight loss, polyuria, and polydypsia, coupled with laboratory investigations such as fasting blood sugar (greater than $6.5 \mathrm{mmol} / \mathrm{L}$ ) and 2-hour postprandial blood sugar (greater than $11 \mathrm{mmol} / \mathrm{L})$. These patients were either referred by the endocrinologist to the eye clinic for ocular examination or discovered to have diabetes mellitus during routine eye clinic examination. Also, participants at meetings of diabetic associations were also included.

A pretested questionnaire was used to obtain information such as age, sex, duration of diabetes, family history of diabetes, type of diabetes, treatment, and associated hypertension. Visual acuity and blood pressure were measured by the eye clinic nurses. The anterior segment of the eye was examined by the ophthalmologist using a bright pen torch, Haag streit 900 slit-lamp biomicroscope, Goldmann applanation tonometer, and four-mirror gonioscope. Amethocaine drops were used as topical anesthetic agent, fluorecein dye (nontoxic) was used to stain the cornea and also in tonometry, and $1 \%$ tropicamide was used to dilate the pupil.

\section{Visual acuity}

This was determined using an illuminated Snellen's chart (placed at 6 meters from the participants) with glasses, if worn. One eye was tested at a time. The last completed line was recorded as the visual acuity for that eye.

Pupillary dilatation was effected using one drop of tropicamide $1 \%$, which was instilled into each eye and repeated after 5-10 minutes. The subjects were instructed to keep their eyes shut after each instillation. Delayed dilatation was implied if pupillary diameter was less than $5 \mathrm{~mm}$ after 40 minutes.

Glaucoma is defined as a multifactorial optic neuropathy with characteristic acquired loss of retinal ganglion cells, atrophy of the optic nerve head typified by pale cupped discs, and characteristic visual field defects. It was assessed using intraocular pressure (IOP), cup:disc ratio, and visual field. Fundoscopy was carried out using a Hamblin or Heinz direct ophthalmoscope. A vertical cup:disc ratio of 0.5 and above was considered abnormal. IOP was measured using a Goldmann applanation tonometer, and IOP greater than $21 \mathrm{mmHg}$ was considered elevated. Gonioscopy using a 
four-mirror lens was used to classify the glaucoma into open- and closed-angle types. Pachymetry and retinal nerve fiber analysis were not carried out at the time of the study, because the necessary equipment was not available.

The data obtained were analyzed using an IBM computer with Statistical Package for Social Sciences (SPSS Inc, Chicago, IL), Version 11.0.

\section{Results}

The findings in 181 patients with diabetes mellitus were analyzed. The age - sex distribution of the patients is as shown in Figure 1, with a male to female ratio of 1.2:1.0. Their ages ranged between 27 years and 83 years, with a mean age of 57.51 years (standard deviation $[\mathrm{SD}] \pm 10.90$ years).

Sixty (33.15\%) patients had a family history of diabetes mellitus. One hundred and two (56.35\%), 31 (17.13\%), 26 (14.37\%), 20 (11.05\%), and two (1.11\%) patients were on oral, diet plus oral, diet alone, insulin alone, and oral plus insulin, respectively.

Seventy-four (40.9\%) patients had associated hypertension. Systolic blood pressure ranged between $100 \mathrm{mmHg}$ and $210 \mathrm{mmHg}$ (mean $133.34 \mathrm{mmHg}$, SD $20.29 \mathrm{mmHg}$ ), while diastolic pressure ranged between $60 \mathrm{mmHg}$ and $130 \mathrm{mmHg}$ (mean $80.80 \mathrm{mmHg}$, SD $11.65 \mathrm{mmHg}$ ).

As shown in Table 1, the findings were warts in 39 (21.55\%) patients, poliosis in $22(12.16 \%)$ patients, chalazia in $14(7.74 \%)$ patients, stye in ten $(5.53 \%)$ patients, dermatochalasis in seven $(3.87 \%)$ patients, ptosis in six $(3.32 \%)$ patients, and orbital cellulitis in one (0.55\%) patient.

Sixty-six (36.50\%), 27 (14.92\%), 26 (14.37\%), and three $(1.66 \%)$ patients had tortuous conjunctival vessels inferiorly, pterygium, pingueculum, and dry eyes, respectively.

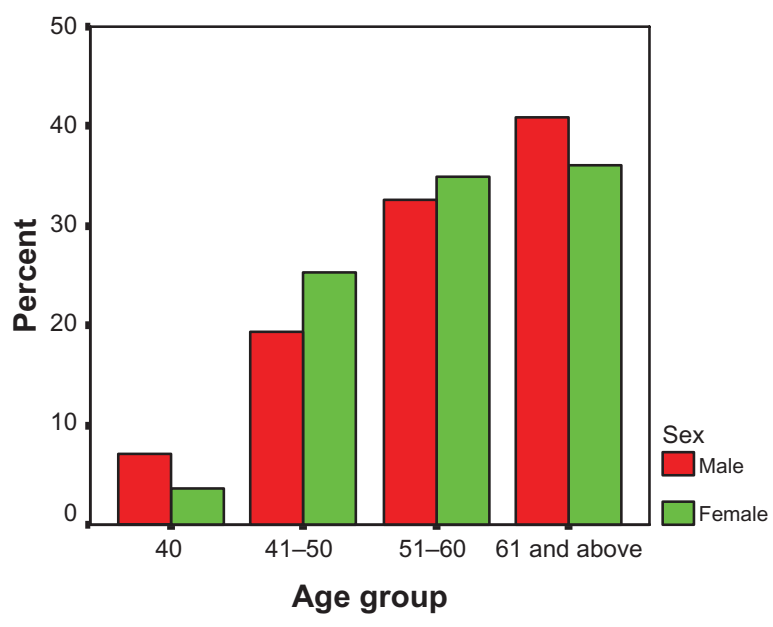

Figure I Age - sex distribution of I8I patients with diabetes (male:female ratio is $1.2: 1.0)$.
Table I Anterior segment findings in 181 diabetic patients

\begin{tabular}{|c|c|}
\hline Findings & $\mathbf{N}(\%)$ \\
\hline \multicolumn{2}{|l|}{ Lid } \\
\hline Warts & $39(21.0)$ \\
\hline Poliosis & $22(12.16)$ \\
\hline Chalazia & $14(7.74)$ \\
\hline Stye & $10(5.53)$ \\
\hline Dermatochalasis & $7(3.87)$ \\
\hline Ptosis & $6(3.32)$ \\
\hline Orbital cellulitis & I $(0.55)$ \\
\hline \multicolumn{2}{|l|}{ Conjunctiva } \\
\hline Tortuous conjunctival vessels & $66(36.50)$ \\
\hline Pterygium & $27(14.92)$ \\
\hline Pingueculum & $26(14.37)$ \\
\hline \multicolumn{2}{|l|}{ Iris } \\
\hline Iris atrophy & $23(12.71)$ \\
\hline Rubeosis iridis & $3(1.66)$ \\
\hline Hyphema & $2(1.11)$ \\
\hline Hypopion & I (0.55) \\
\hline Iris holes & I (0.55) \\
\hline Delay dilatation of pupil & 34 (18.79) \\
\hline Cataract & $119(65.75)$ \\
\hline Glaucoma & $4 \mathrm{I}(22.65)$ \\
\hline
\end{tabular}

Corneal sensitivity was reduced in $25(13.80 \%)$ patients. Ten $(5.53 \%)$ had superficial punctate keratopathy, while one $(0.55 \%)$ each had corneal ulcer and abscess.

Iris findings were iris atrophy in $23(12.71 \%)$ patients, rubeosis iridis in three $(1.66 \%)$ patients, and one $(0.55 \%)$ patient had iris atrophy. Hyphema was found in two $(1.11 \%)$ patients and hypopion in one $(0.55 \%)$ patient.

Dilatation of the pupil was delayed in $34(18.79 \%)$ patients. Cataract was found in $119(65.75 \%)$ patients. IOP ranged between $10 \mathrm{mmHg}$ and $40 \mathrm{mmHg}$ with a mean of $17.38 \mathrm{mmHg}$ (SD $5.85 \mathrm{mmHg}$ ). Forty-one (22.65\%) patients had IOP greater than $21 \mathrm{mmHg}$.

Seventh nerve palsy was found in seven (3.87\%) patients, third palsy in four $(2.21 \%)$ patients, and fourth palsy in one $(0.55 \%)$ patient. No patient had sixth nerve palsy.

The duration of diagnosis varied between 0.25 months and 384 months with a mean duration of 64.97 months (SD \pm 66.34 months).

Table 2 Association between the duration of diabetes mellitus and findings in the anterior segment of the eye

\begin{tabular}{ll}
\hline Anterior segment findings & P-value \\
\hline Lid abnormalities & 0.705 \\
Conjunctival abnormalities & 0.087 \\
Decreased corneal sensitivity & 0.335 \\
Cataract & 0.009 \\
Glaucoma & 0.843 \\
\hline
\end{tabular}


All the six patients who had ptosis had it before 10 years of having diabetes mellitus. Thirty-five $(74.5 \%)$, eleven (78.6\%), 20 (87.0\%), eleven (78.6\%), 43 (86.0\%), $22(88.0 \%), 74(73.3 \%)$, and $30(83.3 \%)$ patients with warts, stye, chalazion, poliosis, tortuous conjunctival vessels, pterygium, cataract, and glaucoma, respectively, had the affliction within 10 years of having diabetes mellitus. However, the only significant association with duration was found with cataract, as shown in Table 1.

The presence of associated hypertension had no significant effect on findings in the anterior segment of the eye.

\section{Discussion}

Diabetes mellitus is a global problem with the greatest frequency in developing countries. ${ }^{1}$ It has been postulated that there is a need for global surveillance programs for primary, secondary, and tertiary prevention of diabetes and its complications. ${ }^{1}$ Also, it has been shown that blinding complications such as diabetic retinopathy can be significantly reduced by early intervention with laser treatment. ${ }^{18}$ Effective treatment therefore has to be initiated at an early stage before the patient is aware of any symptoms. This can be achieved only by systematic screening. This will include identifying those with a family history of diabetes, assessment of visual acuity, and examination of the anterior segment of the eye in all clinics and by all medical practitioners, including general practitioners and primary eye caretakers. Many of the complications of diabetes mellitus may be delayed or prevented by prompt and effective treatment and education. ${ }^{1}$

Diabetes mellitus causes significant morbidity and mortality in multiple systems of the body. Studies in the past have concentrated on diabetic retinopathy; however, almost all layers of the eye are affected. The anterior segment of the eye is easily accessible to nonspecialists who can detect anterior segment features and refer patients promptly to physicians and/or ophthalmologists. Therefore, primary care physicians and other allied health care professionals must be able to recognize the anterior segment findings in diabetes mellitus in order to facilitate screening of all their regular patients and thus prompt referral for detailed posterior segment examination by eye specialists. Early detection and appropriate treatment of diabetic eye disease greatly reduce the risk of vision loss.

This study looked at the findings in the anterior segment of 181 patients with diabetes mellitus. Seventy-four (40.9\%) of them had associated hypertension. This is not uncommon, especially with the noninsulin-dependent type that is seen in adults.
Forty-one $(22.65 \%)$ and $13(7.18 \%)$ of the patients were blind and visually impaired in one or both eyes, respectively. This is high compared with what was found in India. ${ }^{2}$ This difference may be connected with the different methodologies used. Sharma ${ }^{2}$ did a retrospective study on hospital-based patients, and participants of a diabetic association were included in this study.

Common findings in the lids and adnexa were warts, followed by poliosis and chalazia. Diabetes mellitus is a well-documented risk factor for recurrent styes and multiple chalazia. ${ }^{19} \mathrm{~A}$ finding of recurrent styes should therefore arouse further examinations for diabetes mellitus. Of great interest is the finding of tortuous conjunctival vessels, especially in the lower fornix in $66(36.5 \%)$ patients. This is different from the usual conjunctival inflammation, as the vessels are easily isolated from the surrounding conjunctiva, which is not red. Cheung et $\mathrm{al}^{5}$ found a significantly $(P<0.01)$ wider conjunctival vessel diameter in type 2 diabetic patients than in nondiabetic controls. However, a case-control study in future will be able to determine the significance of the findings in this study. A higher occurrence of pterygia (27 [14.92\%] patients) was found in this study compared with what was found in India (four [0.22\%] patients). ${ }^{2}$ The reason for this difference is not clear but may be connected with the different study groups used in the studies. However, it is worth noting that the higher occurrence of pterygia and pinguecula may be due to environmental and/or climatic factors.

Reduction in the corneal sensitivity in diabetes mellitus has been reported ${ }^{13}$ in the literature, as found in this study in $25(13.80 \%)$ patients. Corneal sensitivity is an important ocular defense mechanism, which if lost or reduced may lead to serious corneal problems. ${ }^{20}$

Reduced corneal sensitivity is part of the generalized sensory neuropathy found in diabetes mellitus. ${ }^{20}$ Ruben $^{21}$ found significantly reduced corneal sensitivity in diabetic patients.

The commonest iris finding was atrophy. This, however, may be partly due to aging, as the mean age of the patients was 57.51 years ( $\mathrm{SD} \pm 10.90$ years) or ischemia found in diabetes mellitus. As expected, because of the friable nature of abnormal blood vessels on the iris, hyphema was associated with one of the cases of rubeosis iridis. This rare occurrence was also reported by Kaimbo et al. ${ }^{22}$ Abnormal vessels on the iris in diabetes mellitus are usually associated with advanced diabetic retinopathy, and these may bleed spontaneously.

Clinical findings have shown that the pupils of diabetic patients are difficult to dilate. ${ }^{13} 1 \%$ tropicamide (Mydriacyl), which was used in this study, is a commonly used dilating drop. It acts in 15-30 minutes with a duration of action of 
about 3-8 hours. The pupils were left to dilate for about 40 minutes because it has been found that in black people, by 40 minutes, there is fairly good dilatation (a mean of $5 \mathrm{~mm}){ }^{23,24}$ This is corroborated by this study, as 34 (18.79\%) patients had delayed dilatation of their pupils.

Cataract was quite common in this study (119 [65.75\%] patients), as found by others. ${ }^{2,22,25,26}$ It may, however, be senile, as many of the patients were elderly (mean age of 57.51 years $[\mathrm{SD} \pm 10.90$ years]). It may also be diabetic, especially when seen in the presenile period. IOP was greater than $21 \mathrm{mmHg}$ in $41(22.65 \%)$ patients. This is high compared with findings of other authors $(3.49 \%))^{2,26}$

\section{Conclusion}

The primary care physician and other allied health care professionals must be aware of the anterior segment findings in diabetes mellitus and of their role in referring patients promptly before sight-threatening complications such as diabetic retinopathy occur.

In addition, an effective partnership between the person with diabetes, the primary care physician, and the eye care professional is essential in order to ensure appropriate eye care.

The need for an age-matched case-control study (the object of a future study) cannot be overemphasized.

\section{Acknowledgment}

We appreciate all the doctors, nurses, and hospital maids in the eye clinic who assisted in the collection of data. Our gratitude also goes to participants from the diabetic association who volunteered to be screened. Our gratitude also goes to Oluwadara Adeoti and our coworkers for their assistance in data collation and typing.

\section{Disclosure}

The authors report no conflicts of interest in this work.

\section{References}

1. King H, Rewers M. Diabetes in adults is now a third world problem. Bull WHO. 1991;69(6):643-648.

2. Sharma RA. Diabetic eye disease in Southern India. Community Eye Health. 1996;9(20):56-58.

3. Nwosu SNN. Diabetic retinopathy in Nnewi. Nig J Ophthalmol. 2000;8(1):7-10.

Clinical Ophthalmology

\section{Publish your work in this journal}

Clinical Ophthalmology is an international, peer-reviewed journa covering all subspecialties within ophthalmology. Key topics include: Optometry; Visual science; Pharmacology and drug therapy in eye diseases; Basic Sciences; Primary and Secondary eye care; Patient Safety and Quality of Care Improvements. This journal is indexed on

Submit your manuscript here: http://www.dovepress.com/clinical-ophthalmology-journal
4. Jenkins LM, Mayon-White VA. Screening for diabetic retinopathy Community Eye Health. 1996;9(2):54-56.

5. Cheung AT, Ramanujam S, Greer DA, Kumagai LF, Aoki TT Microvascular abnormalities in the bulbar conjunctiva of patients with type 2 diabetes mellitus. Endocr Pract. 2001;7(5):358-363.

6. Inoue $\mathrm{K}$, Kato $\mathrm{S}$, Ohara $\mathrm{C}$, et al. Ocular and systemic factors relevant to diabetic keratoepitheliopathy. Cornea. 2001;20:798-801.

7. Weston BS, Bourne WM, Polse KA, Hodge DO. Corneal hydration control in diabetes mellitus. Invest Ophthalmol Vis Sci. 1995;36: 586-595.

8. Olsen T, Busted N, Schmitz O. Corneal thickness in diabetes mellitus. Lancet. 1980;1:883.

9. Busted N, Olsen T, Schmitz O. Clinical observation on the corneal thickness and the corneal endothelium in diabetes mellitus. $\mathrm{Br} \mathrm{J}$ Ophthalmol. 1981;65:687-690.

10. Foulks GN, Thofft RA, Pery HD, Tolentino FI. Factors related to corneal endothelial complications after closed vitrectomy in diabetes. Arch Ophthalmol. 1979;97:1076-1079.

11. Perry HD, Foulks GN, Thoft RA. Corneal complications after closed vitrectomy through pars plana. Arch Ophthalmol. 1978;96:1401-1403.

12. Lawrenson JG. Corneal sensitivity in health and disease. Ophthal Physiol Opt Suppl. 1997;17:17-22.

13. Touzeau O, Levet L, Borderie V, Bouchard P, Laroche L. Anterior segment of the eye and diabetes mellitus. J Fr Ophthalmol. 2004;27(8):859-870.

14. Bron AJ, Brown NAP, Harding JJ, Ganea E. The lens and cataract in diabetes. Int Ophthalmol Clinics. 1998;38:37-67.

15. Pardo, G. Neuro-ophthalmological manifestations of diabetes mellitus. Int Ophthalmol Clinics. 1998;38:213-226.

16. Schertzer RM, Wang D, Bartholomew LR. Diabetes mellitus and glaucoma. Int Ophthalmol Clinics. 1998;38:69-87.

17. Mitchell P, Smith W, Chey T, Healey PR. Open-angle glaucoma and diabetes. Ophthalmology. 1997;104:712-718.

18. British Multicentre Study Group. Photocoagulation for proliferative diabetic retinopathy: a randomised control clinical trial using the xenon-arc. Diabetologia. 1984;26:109-115.

19. Harvard Health Foundation. Styes. Available from: http://www. healthcentral.com/encyclopedia/408/709.html. Accessed January 12, 2012.

20. Lawrenson JG. Corneal sensitivity in health and disease. Ophthal Physiol Opt Suppl. 1997;17:17-22.

21. Ruben ST. Corneal sensation in insulin dependent and non-insulin dependent diabetics with proliferative retinopathy. Acta Ophthalmol. 1994;72:576-580.

22. Kaimbo DK, Kabongo BK, Missotten L. Ocular complications in diabetes mellitus in Zaire. Bull Soc Belge Ophthalmol. 1995;255:107-113.

23. Emiru VP. Response to mydriatics in the African. Br J Ophthalmol. 1971;55:538-543.

24. Jude EB, Ryan B, O’Leary BM, Gibson JM, Dodson PM. Pupillary dilatation and driving in diabetic patients. Diabetic Med. 1998;15(2):143-147.

25. Rizval A. Ocular manifestations in diabetes mellitus: an experience at Nepal Medical College Teaching Hospital. Nepal Med Coll J. 2004;6(2): 136-138.

26. Zghal-Mokni I, Nacef L, Letaief I, Mahjoub S, Bouguila H, Blouza S, et al. Ocular manifestations of diabetes. Tunis Med. 2008;86(11): 1004-1007.

\section{Dovepress}

PubMed Central and CAS, and is the official journal of The Society of Clinical Ophthalmology (SCO). The manuscript management system is completely online and includes a very quick and fair peer-review system, which is all easy to use. Visit http://www.dovepress.com/ testimonials.php to read real quotes from published authors. 